\title{
Sampling and Field Procedures of the
}

\section{Pittsburgh Morbidity Survey}

\author{
BY DANIEL G. HORVITZ, B.S.
}

It is clearly recognized that an accurate evaluation of a community's health status requires more than an analysis of mortality data or reports of communicable disease. The lack of current information on the incidence and prevalence of illness and on other health problems in Pittsburgh led to establishing the "Arsenal study area" for concentrated investigation.

During July 1951, the department of biostatistics of the Graduate School of Public Health, University of Pittsburgh conducted a morbidity survey, on a probability sample basis, of households located in the Arsenal study area. First in a planned series of morbidity studies in Pittsburgh, the survey had four objectives: foremost-to provide general measures of the health status of the household population through the collection of data on recent illness, hospitalization, and accident experience; second-to characterize the population under study through the collection of basic social and economic information; third-to provide a general picture of the pattern of demand for health services; and fourth-to furnish the

Mr. Horvitz, assistant professor of biostatistics, University of Pittsburgh Graduate School of Public Health, presented this paper before the Second Conference on Public Health Statistics at the School of Public Health, University of Michigan, Ann Arbor, June 19. nucleus of families to be followed for long-term studies.

Of a total probability sample of 2,954 dwelling units in the Arsenal study area, completed schedules were obtained from 2,791 households, or 94.5 percent. A second sample of 1,629 dwelling units, representing 1 percent of those eligible, was selected from the rest of Pittsburgh. However, this report will be limited to the Arsenal study area sample. It will describe sample and field procedures employed and will discuss the results of a preliminary investigation of both sampling and nonsampling errors.

\section{General Description}

The Arsenal study area is a section of the Arsenal health district, the first of five health districts to be established by a reorganization plan of the Pittsburgh Health Department. Its location is shown on the map. The study area comprises 22 of the 194 census tracts in Pittsburgh. Final 1950 census population figures yield 81,785 persons in the study area. Age figures of this population distributed by sex are not available for 1950. However, comparison of the probability sample with 1950 census data for all Pittsburgh shows no striking differences. These data are presented in table 1.

Preliminary 1950 census data for Pittsburgh (1) indicated that 95.42 percent of the population lived in dwelling units, as defined for the census, with 3.45 persons per unit. When ap- 
Table 1. Age, by sex, for the Arsenal study area sample ${ }^{1}$ and 1950 census of the city of Pittsburgh

\begin{tabular}{|c|c|c|c|c|c|c|c|c|c|}
\hline \multirow{3}{*}{ Age (in years) } & \multicolumn{6}{|c|}{ Arsenal study area sample } & \multicolumn{3}{|c|}{1950 census of Pittsburgh } \\
\hline & \multicolumn{2}{|c|}{ Total } & \multicolumn{2}{|c|}{ Male } & \multicolumn{2}{|c|}{ Female } & \multirow{2}{*}{$\frac{\text { Total }}{\text { Percent }}$} & \multirow{2}{*}{$\begin{array}{c}\text { Male } \\
\text { Percent }\end{array}$} & \multirow{2}{*}{$\begin{array}{l}\text { Female } \\
\text { Percent }\end{array}$} \\
\hline & Number & Percent & Number & Percent & Number & Percent & & & \\
\hline $\begin{array}{l}\text { Under } 5.5 \\
\text { 5-14 } \\
15-24 \\
25-34 \\
\text { 35-444 } \\
45-64 \\
65 \text { and over }\end{array}$ & $\begin{array}{r}849 \\
1,490 \\
1,429 \\
1,548 \\
1,497 \\
2,060 \\
748\end{array}$ & $\begin{array}{r}9 \\
15 \\
15 \\
16 \\
15 \\
21 \\
8\end{array}$ & $\begin{array}{r}441 \\
751 \\
700 \\
740 \\
715 \\
1,008 \\
345\end{array}$ & $\begin{array}{r}9 \\
16 \\
15 \\
16 \\
15 \\
21 \\
7\end{array}$ & $\begin{array}{r}408 \\
739 \\
729 \\
808 \\
782 \\
1,052 \\
403\end{array}$ & $\begin{array}{r}8 \\
15 \\
14 \\
16 \\
16 \\
21 \\
8\end{array}$ & $\begin{array}{r}9 \\
14 \\
14 \\
17 \\
15 \\
23 \\
8\end{array}$ & $\begin{array}{r}9 \\
14 \\
14 \\
17 \\
15 \\
23 \\
8\end{array}$ & $\begin{array}{r}9 \\
14 \\
15 \\
17 \\
15 \\
22 \\
8\end{array}$ \\
\hline No information & 128 & 1 & 38 & 1 & 90 & 2 & - & 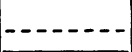 & 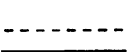 \\
\hline All ages_. & 9,749 & 100 & 4,738 & 100 & 5,011 & 100 & 100 & 100 & 100 \\
\hline
\end{tabular}

1 For 2,791 completed interviews.

plied to the population of the study area, these proportions yield an estimated 78,039 persons in 22,620 eligible dwelling units.

The 1940 census had shown 47 percent of the area's households, also as defined for the census, in the lowest quartile of Pittsburgh with respect to average monthly rent, with 28 percent in the highest quartile, and only 25 percent in the combined middle quartiles. The study area, therefore, may be considered to be well below the rest of the city in income level.

Personal interview with the housewife or other responsible member of each household selected for sampling produced the survey data which included, in addition to the usual demographic characteristics, information for time periods preceding the date of interview as follows :

Prior month-illnesses; and services of physicians, hospitals, and clinics.

Prior year-hospitalizations; accidents or injuries requiring hospitalization or a physician's care; and services of specialists, dentists, public health nurses, and clinics.

\section{Design and Method of Sampling}

Because no accurate lists were available of the eligible dwelling units in the selected area, a design using area sampling was adopted ( $(2)$. First, 468 census blocks (1940) were classified into three strata according to the number of dwelling units occupied in 1940: stratum I- large blocks, 100 or more; stratum $\mathrm{II}$-medium blocks, 50 to 100 ; stratum III-small blocks, less than 50 (see table 2).

Blocks which in 1940 had no occupied dwelling units, or "zero" blocks, were joined with nonzero blocks. Where examination of building permits issued after January 1, 1940, revealed sufficient construction, certain blocks were reclassified. One entire census tract, which had changed greatly since 1940, was cruised by automobile to estimate the number of occupied dwelling units.

To insure a better spread of the sample over the area, we designated blocks as the primary sampling units, and introduced the individual dwelling as the subsampling unit within the selected blocks. Our decision to subsample the blocks meant listing all eligible dwelling units in each block, a task which was performed by enumerators.

Because there were no published data on the amount of variation between blocks and between households within blocks for characteristics of illness and hospitalization for specified periods, we had no basis for estimating the optimum proportion of blocks and of households to be sampled in order to achieve a specified precision. To lead to an approximation of such proportions, we adopted a method suggested by Hansen (3). The method includes the use of the same proportion of sample households for all strata. Determination of this pro- 
portion requires a decision on the total number of households to select for the sample.

Since the size of sample to be selected depends upon the phenomenon to be studied, we based the sample size on estimates from other surveys of the rates for number of persons hospitalized per 1,000 population per year and number ill in the course of a month per 1,000 population. These rates are within the order of magnitude of the other phenomena examined in the survey. We also decided that the size of the sample should be such that the observed rate should not differ by chance from the true rate by more than 10 percent. In the light of these considerations, and assuming random sampling, a sample of 8,900 individuals was determined, but it was arbitrarily enlarged to 10,000 to adjust for the actual plan of sampling blocks and then households rather than individuals in an unrestricted random fashion. By translating the 10,000 individuals into number of households, a sampling ratio of 2 of every 15 dwelling units was calculated, yielding an expected 2,927 households to be sampled.

In selecting the number of blocks for the sample, we included all 36 blocks in stratum I (100 or more occupied dwelling units), for undoubtedly there would be substantial variation between those blocks for the characteristics to be measured. We followed Hansen's (3) scheme in allocating the block and subsampling rates to the strata containing the medium- and small-size blocks. Although Hansen suggests selecting an average of 5 dwelling units from the blocks in the small-block stratum, we selected 9 for two reasons: First, the time al-

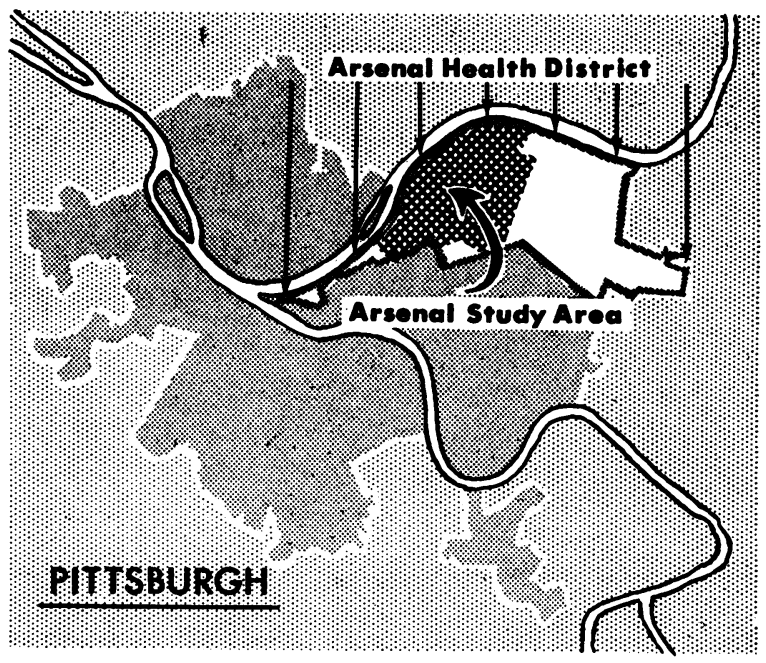

lotted for the field work would permit only the listing of about 50 percent of the blocks; second, since the morbidity survey would be directed partly toward specific illness diagnoses-items which occur rarely in the population-it was felt that heavier sampling within the block would improve the efficiency of the survey for these items.

In tables 2 and and 3 are shown the block and dwelling unit sampling rates, and the expected and actual number of dwelling units selected from each stratum.

To accomplish the sample block selection, census tracts in the study area were listed with each tract geographically contiguous to the immediately preceding tract. Then, maintaining the 1940 census numerical order of the blocks within census tracts, a list of blocks eligible for selection in the sample was prepared for each stratum. The actual selection was carried out

Table 2. Block sampling summary-Arsenal study area

\begin{tabular}{|c|c|c|c|c|c|c|}
\hline Stratum & $\begin{array}{l}\text { Number } \\
\text { of eligible } \\
\text { blocks }\end{array}$ & $\begin{array}{c}\text { Estimated } \\
\text { number of } \\
\text { eligible } \\
\text { dwelling } \\
\text { units }{ }^{1}\end{array}$ & $\begin{array}{l}\text { Estimated } \\
\text { average } \\
\text { number of } \\
\text { eligible } \\
\text { dwelling } \\
\text { units per } \\
\text { block }\end{array}$ & $\begin{array}{l}\text { Block } \\
\text { sampling } \\
\text { rate (pro- } \\
\text { portion } \\
\text { selected) }\end{array}$ & $\begin{array}{l}\text { Number } \\
\text { of blocks } \\
\text { selected }\end{array}$ & $\begin{array}{c}\text { Actual } \\
\text { number of } \\
\text { eligihle } \\
\text { dwelling } \\
\text { units in } \\
\text { selected } \\
\text { blocks }\end{array}$ \\
\hline II $_{\text {II }}$ & $\begin{array}{r}36 \\
150 \\
282\end{array}$ & $\begin{array}{r}4,149 \\
10,117 \\
7,689\end{array}$ & $\begin{array}{r}115.2 \\
67.4 \\
27.3\end{array}$ & $\begin{array}{l}1 / 1 \\
3 / 5 \\
2 / 5\end{array}$ & $\begin{array}{r}36 \\
90 \\
113\end{array}$ & $\begin{array}{l}4,384 \\
5,907 \\
3,175\end{array}$ \\
\hline All strata_. & 468 & 21,955 & 46. 9 & $51 / 100$ & 239 & $--1-2-1-2$ \\
\hline
\end{tabular}

1 Source: 1940 Census, Housing Statistics by Block for Pittsburgh. These data were adjusted upwards where multiple dwellings had been constructed since 1940 . 
systematically, beginning with a block chosen at random from the list. For example, selection from the small-block stratum was accomplished by choosing two numbers between 1 and 5 at random (since the sampling rate was 2 in 5), and by designating for the sample the blocks with these list numbers plus every fifth block following each so selected.

A systematic procedure, using a random starting point and skip-interval in accordance with the appropriate sampling rate, was also fol- lowed in selecting the dwelling units to be enumerated in each of the sample blocks.

There are many possible sample designs alternative to that adopted for the morbidity survey. Undoubtedly, there exist schemes for sampling urban populations which would achieve the desired precision at less cost. However, it is impossible to determine in advance the value of reasonable alternative plans in the absence of information essential to the design of efficient sampling systems for morbidity sur-

\section{Defermination of the Sampling Rates for the Arsenal Study Area Survey}

\section{Over-all Rates}

To estimate a true rate of 100 per 1,000 , or 1 in 10 , from a sample with a small chance that the error of the estimate exceeds 10 percent, the required sample size for unrestricted random sampling without replacement may be obtained from the formula $n=\frac{N}{1+\frac{N p C^{2}}{1-p}}$ where the quantity $N$ is the total size of the population (sampling units), $n$ is the sample size, $p$ the true proportion possessing the attribute, and $C$ the desired coefficient of variation.

For the survey, we have $p=1 / 10, N=80,000$ persons, and $C=.03$, so that the required $n$ is 8,900 . By arbitrarily increasing 8,900 to 10,000 - to account for the actual plan to select households rather than individuals - the proportion of the eligible individuals desired in the sample is estimated to be $\frac{10,000}{80,000}$ or $1 / 8$.

This rate was increased to 1 in 7.5, or 2 in 15 , to compensate for the nonresponse among those selected for the sample, and since the estimate from census data of the number of persons residing in eligible dwelling units was slightly less than 80,000 .

\section{Block and Dwelling Unit Rates}

Steps in the determination of the block and dwelling unit sampling rates for the medium and small blocks, strata II and III, follow :

1. The over-all sampling was set at 2 out of every 15 eligible dwelling units.

2. The expected average number of dwelling units to be selected from the blocks in stratum III was set at 9. Since the advance estimate of the average size of these blocks was 27 , the dwelling unit sampling rate within blocks was set at $9 / 27$ or 1 in 3 for this stratum.

3 . Since the product of the block and withinblock sampling rates for each stratum must equal the over-all dwelling unit sampling rate of $2 / 15$, the proportion of blocks to be drawn from stratum III was determined to be $2 / 15 \div$ $1 / 3=2 / 5$.

4. The block sampling rate for stratum II is given by the formula

$$
\sqrt{\frac{\text { average size of medium blocks (stratum II) }}{\text { average size of small blocks (stratum III) }}} \times \text { block sampling rate for stratum III or }
$$

$$
\sqrt{\frac{67}{27}} \times 2 / 5=3 / 5 \text {. }
$$

5. The proportion of eligible dwelling units to select from each of the stratum II sample blocks was then determined from the over-all sampling rate to be $2 / 15 \div 3 / 5=2 / 9$. 
Table 3. Dwelling unit sampling summary-Arsenal słudy area

\begin{tabular}{|c|c|c|c|c|c|c|}
\hline Stratum & $\begin{array}{l}\text { Dwelling unit } \\
\text { sampling rate } \\
\text { (within blocks) }\end{array}$ & $\begin{array}{l}\text { Expected } \\
\text { sample } \\
\text { number of } \\
\text { of dwelling } \\
\text { units }\end{array}$ & $\begin{array}{l}\text { Actual number } \\
\text { of dwelling } \\
\text { units selected }\end{array}$ & $\begin{array}{l}\text { Number of } \\
\text { selected } \\
\text { households } \\
\text { interviewed }\end{array}$ & $\begin{array}{l}\text { Number of } \\
\text { selected house- } \\
\text { holds not } \\
\text { interviewed }\end{array}$ & $\begin{array}{l}\text { Average number } \\
\text { dwelling units } \\
\text { selected } \\
\text { per block }\end{array}$ \\
\hline IIIII & $\begin{array}{l}2 / 15 \\
2 / 9 \\
1 / 3\end{array}$ & $\begin{array}{r}553 \\
1,349 \\
1,025\end{array}$ & $\begin{array}{r}576 \\
1,322 \\
1,056\end{array}$ & $\begin{array}{r}537 \\
1,255 \\
999\end{array}$ & $\begin{array}{l}39 \\
67 \\
57\end{array}$ & $\begin{array}{r}16.0 \\
14.7 \\
9.3\end{array}$ \\
\hline All strata & - & 2,927 & 2,954 & 2,791 & 163 & \\
\hline
\end{tabular}

veys. But the sampling scheme used for this survey does possess features of practical and theoretical importance:

First, it is a probability sampling scheme with respect to dwelling units since the chance of being included in the sample, namely, $2 / 15$, is known for every eligible dwelling unit. Therefore, the reliability of estimates determined from the sample can be assessed from the sample data.

Second, it takes into account, although limitedly, the possible relationship of the measured characteristics to size of block or primary sampling unit.

Third, its procedures are simple to administer and control-the determination of the block and subsampling rates and the sample selection can be accomplished rapidly.

\section{Training of Enumerators}

Of 18 enumerators employed for the field survey, 10 were male and 8 were female. All of the males and 2 of the females were medical students at the University of Pittsburgh School of Medicine but had no previous interviewing experience. The other 6 female enumerators, chosen from applicants with and without interview experience, included 2 graduate and 3 undergraduate students at the university and an enumerator experienced in health surveys.

The training program, which ran for 3 days before the field survey, thoroughly covered the survey's purpose, field procedures, interviewing techniques, and schedule. As part of their training, which was also supplemented by an instruction manual covering all aspects of the survey, the enumerators conducted practice interviews.
Field Procedures

The actual field work began June 28, 1951. The Arsenal study area was divided, without cutting across census tract boundaries, into six relatively homogeneous subareas determined to a great extent by natural topography. Sample blocks were assigned at random to the enumerators subject to the conditions that each enumerator's assignment include $(a)$ at least two - blocks in each subarea and (b) two large, five medium, and either six or seven small blocks. The latter condition was applied to distribute the work load evenly. The assignments were ordered to insure that the field work would be conducted in approximately the same time period in each subarea.

The sample blocks were assigned at random to permit unambiguous statistical examination of the degree of agreement with respect to the findings among enumerators.

No substitutions by the enumerator were permitted for the dwelling units selected. Callbacks, up to a total of three, were made to sample households not contacted on the first call.

To keep the refusal rate low, Pittsburgh radio and television stations made periodic public service announcements asking the public's cooperation during the field portion of the survey, which had been preceded by newspaper publicity.

Close contact was maintained with the enumerators during all phases of the field work, and frequent meetings were held to correct any errors appearing on completed schedules.

Except for a relatively small number of callbacks, the field work was completed in a little over 4 weeks. 


\section{Cost}

Actual costs of the various phases of the morbidity survey in the study area, except for the tabulation of the results, are shown:

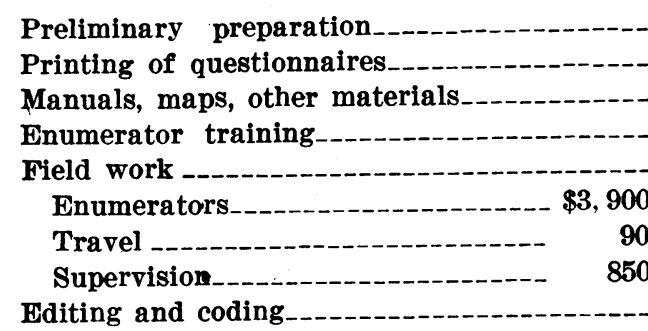

Total

Cost per completed, coded schedule
$\$ 475$

250

243

540

4,840

2,100

8,448

$\$ 3.03$
Not included are the salaries of the survey's director and assistant director. No attempt was made to determine the proportion of departmental overhead assignable to the survey. There was no overhead for the field office. Énumerators were paid $\$ 1.25$ an hour but were not restricted to an 8-hour day. Two punch cards were coded: one for each household and one for each individual in the sample.

The enumerators kept records of their travel and interview time as well as the total time spent in each assigned block. Of their total field time, 36 percent was spent in interviewing, 10 percent in traveling, and 54 percent in other activities which included listing dwelling units.

\section{Accuracy}

The increasing demand for morbidity data on a sample basis emphasizes the need for thorough study of both the sampling and nonsampling errors arising in health surveys of the type we are describing. An attempt partly to fulfill this need, based on the results of the Pittsburgh morbidity survey, is under way. For the present, the type of investigation needed will be illustrated for several problems of methodology by analysis of a single characteristic-the number of persons reported ill for the month prior to interview.

\section{Sampling Errors}

In any sample survey, it is essential to evaluate the precision of the results. The equations for calculating precision depend entirely on the sample design and certain properties of the population sampled.

For the Arsenal study area the sample yielded an estimated 8,121 persons ill in the month prior to interview. The estimated coefficient of variation, or rèlative standard error, is 4.04 percent. Using a 95-percent confidence interval for the total of persons ill in the study area during the survey period, we were reasonably assured that a complete population count, using the same definitions, techniques, and enumerators, would have yielded a figure between 7,465 and 8,777 ill persons. Since a rate based on the total population is estimated with greater precision than the absolute numbers, the sampling error for the estimated illness rate of 113 per 1,000 persons in the study area quite likely falls within the goal set in advance.

Computation of the sampling precision for the illness characteristic yielded several quantities of importance to the design of future morbidity surveys, particularly to those contemplating similar surveys of urban populations (table 4). In particular, these quantities were the variances, or measures of variability, between blocks and between households within blocks. Prior knowledge of these variances would have permitted an advance estimate of the precision of the results with the specific design adopted. More important, the block and household sampling rates which would have yielded the desired precision with the least expenditure could have been determined.

Examination of the data in table 4 reveals some interesting facts. The between-block variation and the average number of persons ill per block are both almost directly proportional to the average size of the blocks in each stratum. And the average variance between dwelling units within blocks remains reasonably constant over the three strata.

Clearly, there is some advantage to selecting a sample design which takes into account the variation in block size either by stratification or by sampling with probability proportionate to size. However, it does not appear necessary to vary the number of dwelling units selected for the sample with the size of block.

Sample surveys of human populations, and morbidity surveys especially, are costly. Until the experience of past surveys is evaluated and 
Table 4. Estimated block and average within-block variances and other data by strata for the number of persons reported ill in the month prior to interview-Arsenal study area

\begin{tabular}{|c|c|c|c|c|}
\hline \multirow{2}{*}{ Line } & \multirow{2}{*}{ Quantity } & \multicolumn{3}{|c|}{ Stratum } \\
\hline & & I & II & III \\
\hline $\begin{array}{l}1 \\
2 \\
3 \\
4 \\
5 \\
6 \\
7\end{array}$ & $\begin{array}{l}\text { Number of blocks } \\
\text { Average number of dwelling units per block } \\
\text { Variance between blocks } \\
\text { Average variance between dwelling units within blocks } \\
\text { Average number of persons ill per block } \\
\text { Average number of persons ill per household. } \\
\text { Between blocks coefficient of variation squared (line } 3 \text { divided by square of } \\
\text { line 5) } \\
\text { Within blocks coefficient of variation squared (line } 4 \text { divided by square of } \\
\text { line 6) }\end{array}$ & \begin{tabular}{|l}
36 \\
122 \\
489.5 \\
$\quad .40$ \\
44.1 \\
.362 \\
.25 \\
3.0
\end{tabular} & $\begin{aligned} & 150 \\
& 66 \\
& 214 . 4 \\
& 24 . 42 \\
& . 369 \\
& .37 \\
& 3.1\end{aligned}$ & $\begin{aligned} & 282 \\
& 28 \\
& 80 . 8 \\
& 10 . 35 \\
& . 365 \\
& . 77 \\
& 2 . 6\end{aligned}$ \\
\hline
\end{tabular}

reported, there can be little hope for the development of methods and techniques which will be entirely satisfactory both administratively and statistically.

\section{Nonsampling Errors}

In surveys of this type, there are other sources of error which may cause bias in the results but which would still exist if the investigation had called for canvassing the entire eligible population. They include failure to interview all households selected for sampling, errors of response, and errors attributable to enumerators. Some aspects of these nonsampling errors have been examined for this survey.

For various reasons, 163 households, or 5.5 percent of those selected, were not interviewed. Of these, 67 (2.2 percent) were not contacted during any of the four calls made, and 79 (2.7 percent) refused to cooperate (table 5).

The actual bias in the final estimates from failure to achieve 100 -percent completion can be evaluated properly only by interviewing the nonrespondents. Various statistical techniques for alternative treatment of the "not-at-home" problem, a component of the nonresponse error, are available, however $(4-6)$. For the most part, these techniques constitute attempts to control the extent of this error in a given survey. Nevertheless, it is important to the methodology of morbidity surveys to know when it is necessary to apply them. It is therefore pertinent to know for which health characteristics, and to what extent, the results will differ in households available for interview from those not available.
A tentative answer is afforded by examining the differences among the results for the interview households classified according to the call completing the interview (table 6). If the purpose of our survey had been only to obtain a rate for general illness in the survey population, the data in table 6 indicate that a single call might have sufficed. The difference in the illness rate for the households interviewed on the first call from that of all households interviewed is well within the sampling error for this characteristic. The slight tendency for the illness rate to increase with successive calls may or may not be real.

Interviewing a single respondent for everyone residing in a selected dwelling unit is another source of possible bias in a morbidity survey. Accordingly, in table 7 the age specific rates for general illness reported for the month prior to interview are compared for respond-

Table 5. Distribution of selected households by interview classification-Arsenal study area

\begin{tabular}{|c|c|c|}
\hline Interview classification & Number & Percent \\
\hline $\begin{array}{l}\text { Interviews completed } \\
\text { On 1st call } \\
\text { On 2d call } \\
\text { On 3d call } \\
\text { On 4th call } \\
\text { Interviews not completed } \\
\text { Refusals } \\
\text { Unable to contact in } 4 \text { calls } \\
\text { Respondent unable to answer } \\
\text { (language difficulty, deaf, other) } \\
\text { Dwelling unit vacant on 2d or } \\
\text { succeeding calls }\end{array}$ & $\begin{array}{r}2,791 \\
2,090 \\
500 \\
135 \\
66 \\
163 \\
79 \\
67 \\
9 \\
8\end{array}$ & $\begin{array}{r}94.5 \\
\text { 70. } 8 \\
16.9 \\
4.6 \\
2.2 \\
\text { 5. } 5 \\
2.7 \\
2.2 \\
.3 \\
.3\end{array}$ \\
\hline Total households selected & 2,954 & 100. 0 \\
\hline
\end{tabular}


Table 6. Persons ill per 1,000 during month prior to date of interview by number of call on which inferview was completed-Arsenal study area

\begin{tabular}{|c|c|c|c|}
\hline Call No. & $\begin{array}{l}\text { Number } \\
\text { of per- } \\
\text { sons }\end{array}$ & $\begin{array}{l}\text { Number } \\
\text { of per- } \\
\text { sons ill }\end{array}$ & $\begin{array}{c}\text { Persons } \\
\text { ill per } \\
1,000\end{array}$ \\
\hline 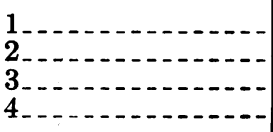 & $\begin{array}{r}7,559 \\
1,621 \\
394 \\
175\end{array}$ & $\begin{array}{r}848 \\
185 \\
45 \\
25\end{array}$ & $\begin{array}{l}112.2 \\
114.1 \\
114.2 \\
142.9\end{array}$ \\
\hline Total _..... & 9,749 & 1,103 & 113. 1 \\
\hline
\end{tabular}

ents and nonrespondents by age groups and sex. Although sampling errors for these rates have not been computed, chi-square tests, which assume unrestricted random sampling, reveal significant differences for all groups except for those males and females in the 15-24 and 45-64 age groups, respectively. Possible alternative hypotheses which might account for these differences have not been examined in detail.

From the data in table 7, it is clear that error might be introduced by depending on a single respondent's report of illness experienced by other members of his household. This source of bias in the returns can be removed by selecting individuals at random for interview rather than households, or by personally interviewing in selected households all respondents above a specified age. Either procedure would increase the survey's cost. Alternatively, the extent of this bias, if it is real, can be reduced by better designed questions and by improved interviewing techniques. The data shown by no means provide the final answer to the problem. Further investigation of this type of response error is necessary for this and other variables relating to health.

In planning morbidity surveys, the type of enumerator employed is an important consideration. It is essential to the success of a survey that interviewing errors not only be measurable but controllable. Standard interviewing techniques and thorough training in them may easily be insignificant control mechanisms when compared with enlightened selection of type and number of enumerators. As yet, no definite criteria are established for the selection of enumerators for health surveys, although the enumerator assignment plan for the Arsenal study area was introduced in an attempt to solve this problem in part. Random assignment. to blocks or primary sampling units, so essential to valid comparison of enumerator groups, also permits their contribution to the total survey error to be measured. Hansen and others $(n)$ discuss this latter aspect and describe a method for determining the optimum number of enumerators for effective control of the enumerator variance.

Table 7. Age specific illness rates per 1,000 for the month prior to interview by sex for respondents and nonrespondents-Arsenal study area

\begin{tabular}{|c|c|c|c|c|c|c|c|c|c|c|c|c|}
\hline \multirow{4}{*}{$\begin{array}{c}\text { Age } \\
\text { (in years) }\end{array}$} & \multicolumn{6}{|c|}{ Male } & \multicolumn{6}{|c|}{ Female } \\
\hline & \multicolumn{3}{|c|}{ Respondents } & \multicolumn{3}{|c|}{ Nonrespondents } & \multicolumn{3}{|c|}{ Respondents } & \multicolumn{3}{|c|}{ Nonrespondents } \\
\hline & \multirow[b]{2}{*}{$\begin{array}{l}\text { Not } \\
\text { ill }\end{array}$} & \multicolumn{2}{|c|}{ Ill } & \multirow[b]{2}{*}{$\begin{array}{l}\text { Not } \\
\text { ill }\end{array}$} & \multicolumn{2}{|c|}{ Ill } & \multirow[b]{2}{*}{$\begin{array}{l}\text { Not } \\
\text { ill }\end{array}$} & \multicolumn{2}{|c|}{ Ill } & \multirow[b]{2}{*}{$\begin{array}{l}\text { Not } \\
\text { ill }\end{array}$} & \multicolumn{2}{|c|}{ Ill } \\
\hline & & $\underset{\text { ber }}{\text { Num- }}$ & $\begin{array}{c}\text { Rate } \\
\text { per } \\
1,000\end{array}$ & & $\underset{\text { ber }}{\text { Num- }}$ & $\begin{array}{c}\text { Rate } \\
\text { per } \\
1,000\end{array}$ & & $\underset{\text { ber }}{\text { Num- }}$ & $\begin{array}{c}\text { Rate } \\
\text { per } \\
1,000\end{array}$ & & $\underset{\text { ber }}{\text { Num- }}$ & $\begin{array}{c}\text { Rate } \\
\text { per } \\
1,000\end{array}$ \\
\hline \multirow{2}{*}{$\begin{array}{l}15-24 \\
25 \text { and over. } \\
45-64 \\
\quad \text { All ages.-- }\end{array}$} & $\begin{array}{r}48 \\
186 \\
155 \\
69\end{array}$ & $\begin{array}{r}2 \\
23 \\
28 \\
24\end{array}$ & $\begin{array}{r}40 \\
110 \\
153 \\
258\end{array}$ & $\begin{array}{r}608 \\
1,154 \\
731 \\
204\end{array}$ & $\begin{array}{l}29 \\
70 \\
76 \\
42\end{array}$ & $\begin{array}{r}46 \\
57 \\
94 \\
171\end{array}$ & $\begin{array}{l}172 \\
927 \\
584 \\
141\end{array}$ & $\begin{array}{r}33 \\
159 \\
123 \\
74\end{array}$ & $\begin{array}{l}161 \\
146 \\
174 \\
344\end{array}$ & $\begin{array}{l}474 \\
433 \\
262 \\
137\end{array}$ & $\begin{array}{l}36 \\
43 \\
59 \\
46\end{array}$ & $\begin{array}{r}71 \\
90 \\
184 \\
251\end{array}$ \\
\hline & 458 & 7.7 & 144 & 2,697 & 217 & 74 & 1,824 & 389 & 176 & 1,306 & 184 & 123 \\
\hline
\end{tabular}

Note: Individuals not responding on age and/or illness and households for which the respondent is unknown are excluded. 
Although the enumerator team in the Pittsburgh survey could have been composed entirely of medical students, the necessity for an objective answer to their advantages or disadvantages led to the actual distribution selected. In table 8 are shown the illness rates obtained by each enumerator.

Table 8. Persons ill per 1,000 in the month prior to interview by enumerator-Arsenal study area

\begin{tabular}{|c|c|c|c|}
\hline $\begin{array}{c}\text { Enumerator } \\
\text { No. }\end{array}$ & $\begin{array}{l}\text { Number } \\
\text { of per- } \\
\text { sons in } \\
\text { house- } \\
\text { holds } \\
\text { inter- } \\
\text { viewed }\end{array}$ & $\begin{array}{l}\text { Number } \\
\text { of persons } \\
\text { reported } \\
\text { ill }\end{array}$ & $\begin{array}{c}\text { Persons } \\
\text { ill per } \\
1,000\end{array}$ \\
\hline 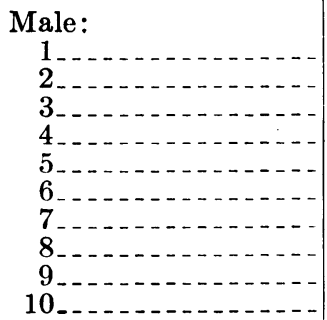 & $\begin{array}{l}621 \\
506 \\
655 \\
706 \\
623 \\
552 \\
476 \\
467 \\
509 \\
464\end{array}$ & $\begin{array}{l}47 \\
77 \\
77 \\
76 \\
68 \\
79 \\
32 \\
47 \\
77 \\
73\end{array}$ & $\begin{array}{r}75.7 \\
152.2 \\
117.5 \\
107.6 \\
109.1 \\
143.1 \\
67.2 \\
100.6 \\
151.3 \\
157.3\end{array}$ \\
\hline All males.... & 5,579 & 653 & 117.0 \\
\hline $\begin{array}{l}\text { Female: } \\
11 \\
21 \\
4 \\
4 \\
5 \\
6 \\
8\end{array}$ & $\begin{array}{l}600 \\
441 \\
642 \\
610 \\
592 \\
478 \\
499 \\
308\end{array}$ & $\begin{array}{l}99 \\
71 \\
79 \\
50 \\
42 \\
46 \\
43 \\
20\end{array}$ & $\begin{array}{r}165.0 \\
161.0 \\
123.1 \\
82.0 \\
70.9 \\
96.2 \\
86.2 \\
64.9\end{array}$ \\
\hline All females_. _. & 4,170 & 450 & 107.9 \\
\hline All enumerators. & 9,749 & 1,103 & 113.3 \\
\hline
\end{tabular}

1 Medical students. All male enumerators were medical students.

We made approximate tests of significance among the enumerators by computing the analysis of variance appropriate to the assignment plan (table 9). This analysis indicated the enumerators to be a heterogeneous group with respect to the rates obtained for ill persons per household. However, the rate difference between male and female enumerators is not substantiated as significant (table 8). Although not independent of the comparisons chosen for the analysis of variance, a test of the medical student rate of 124.3 ill persons per 1,000 and the nonmedical student rate of 89.5 yielded conclusive evidence that the difference in reporting of ill persons to these groups cannot be ascribed to chance. This is not surprising since the female medical students had much more illness reported than the other female enumerators. The remaining comparisons tested revealed significant variation among the illness rates for both the male and female nonmedical student enumerators. The rates for the two female medical students were remarkably consistent, however.

Although limited to a single characteristicillness - the results of this analysis indicate not only the need but the direction for further study of the response problem. If the response bias in reporting persons ill in households is to be effectively controlled in future morbidity surveys, it is essential to know whether, and if so to what extent, respondents tend to over-report to enumerators with medical training. Conversely, is there a tendency to under-report illness to nonmedically trained female enumerators?

Of further concern in the present survey is the actual contribution of the enumerators to the total sampling variance of an observed mean or total. For an unrestricted random sample of $n$ households with $k$ enumerators,

Table 9. Analysis of variance for enumerator study for number of persons ill per household in the month prior to interview-Arsenal study area

\begin{tabular}{|c|c|c|}
\hline Source of variation & $\begin{array}{l}\text { Degrees } \\
\text { of } \\
\text { freedom }\end{array}$ & $\begin{array}{l}\text { Mean } \\
\text { square }\end{array}$ \\
\hline $\begin{array}{l}\text { Assignment areas } \\
\text { Enumerators } \\
\text { Males vs. females } \\
\text { Among males } \\
\text { Among medical student females. } \\
\text { Among other females. } \\
\text { Medical student females vs. } \\
\text { other females. } \\
\text { Enumerators X assignment areas.- } \\
\text { Blocks within enumerator-assign- } \\
\text { ment areas } \\
\text { Households within blocks. }\end{array}$ & $\begin{array}{r}5 \\
17 \\
1 \\
9 \\
1 \\
5 \\
1 \\
85 \\
131 \\
2,546\end{array}$ & $\begin{array}{r}0.77 \\
11.96 \\
1.49 \\
1.57 \\
2.05 \\
1.09 \\
134.87 \\
.38 \\
.43 \\
.59\end{array}$ \\
\hline Total.... & 2,784 & .58 \\
\hline
\end{tabular}

1 Significant at 1-percent level.

2 Significant at 5-percent level. 
each assigned an equal number of households at random, the total sampling variance of an observed mean $\bar{x}$ is given approximately by

$$
\sigma_{x}^{2}=\frac{\sigma^{2}}{n}+\frac{\sigma_{e}^{2}}{k}
$$

The quantities $\sigma_{e}{ }^{2}$ and $\sigma^{2}$ denote, respectively, the enumerator variance and the random sampling variance of the average response for each sampling unit for all enumerators.

Although the actual sample design was not of the unrestricted random variety, this formula may be used to indicate the relative importance of the enumerator variance. An approximate estimate of $\sigma_{e}^{2}$ may be obtained from the analysis of variance table by subtracting the interaction mean square from the mean square for enumerators and dividing by the average number of households interviewed per enumerator. The desired estimate is therefore

$$
s_{6}^{2}=\frac{1.96-.38}{155}=.01 \text {. }
$$

The total mean square in the analysis of variance, or 0.58 , may be taken as indicative of $\sigma^{2}$. Thus, the total sampling variance of the observed mean number of persons reported ill per household for an unrestricted random sample of 2,785 households with 18 enumerators is estimated approximately by

$$
8_{x}^{2}=\frac{.58}{2,785}+\frac{.01}{18}=.00021+.00055=.00076 .
$$

The enumerator variance is, therefore, roughly estimated to be contributing $55 / 76$, or 72 percent, of the total sampling variance.

Although the relative sampling error remains small in this instance, the example does emphasize the importance of evaluating and reporting the contribution of the enumerators to the total survey error, a generally neglected practice. Admittedly, it may not be necessary to do so for many characteristics. Which variables require assessment are not presently known. If the relative magnitude of the enumerator variability had been realized prior to the Pittsburgh morbidity survey, statistical control of this source of error could have been affected by increasing the number of enumerators-if cost of the survey were not an important factor too!
Better criteria for selecting enumerators for morbidity surveys, improved questionnaire design, improved interviewing techniques, and better training methods must be considered in conjunction with the number of enumerators if the enumerator error is to be controlled efficiently.

\section{Summary}

The first of a series of morbidity surveys on a sample basis planned for the Arsenal study area of Pittsburgh is discussed. The survey design, method of selecting the sample, and field procedures are described in detail. In addition, the accuracy of the findings for a single characteristic-persons ill during the month prior to interview -is discussed with respect to both sampling and nonsampling errors. Particular reference in the discussion of the latter is made to the errors of nonresponse, of respondents, and of enumerators.

\section{ACKNOWLEDGMENTS}

Drs. Antonio Ciocco and Paul M. Densen, Department of Biostatistics, University of Pittsburgh Graduate School of Public Health, contributed many valuable suggestions during the preparation of this report.

\section{REFERENCES}

(1) U. S. Bureau of the Census: Housing characteristics of the Pittsburgh, Pa., standard metropolitan area, April 1, 1950. 1950 Census of Housing; Series HC-3, No. 37. June 7, 1951.

(2) Hansen, M. and Hauser, P. : Area sampling-Some principles of sample design. Pub. Opinion Quart. 9: 183-193 (1945).

(3) Hansen, Morris H.: Sampling human populations. Paper presented at the 25th Session of the International Statistical Institute. September 1947.

(4) Birnbaum, Z. W., and Sirken, Monroe G.: Bias due to nonavailability in sampling surveys. $J$. Am. Stat. Assoc. 45: 98-111 (1950).

(5) Hansen, Morris H., and Hurwitz, William N. : The problem of nonresponse in sample surveys. $J$. Am. Stat. Assoc. 41: 517-529 (1946).

(6) Politz, Alfred, and Simmons, Willard : An attempt to get "not at homes" into the sample without callbacks. J. Am. Stat. Assoc. 44: 9-31 (1949).

(y) Hansen, Morris H., Hurwitz, William N., Marks, Ell \$., and Mauldin, W. Parker : Response errors in surveys. J. Am. Stat. Assoc. 46: 147-190 (1951). 